\title{
DESAFIOS E POSSIBILIDADES DA PESQUISA AUTOETNOGRÁFICA
}

\author{
Rosane de Mello Santo Nicola ${ }^{1}$ e Dilmeire Sant'Anna Ramos Vosgerau \\ 1,2Pontifícia Universidade Católica do Paraná, Brasil. 'rosane.nicola@pucpr.br; ²dilmeirerv@gmail.com
}

\begin{abstract}
Resumo. Este artigo visa descrever um encaminhamento metodológico adotado para a pesquisa qualitativa com estrutura interpretativa voltada ao construtivismo social, no qual o pesquisador busca entender o mundo em que trabalha e desenvolve significados subjetivos das experiências. Nessa concepção, estabelece-se articulação entre procedimentos de autoetnografia, etnografia e técnicas de Análise do Discurso, amparada na concepção de que os estudos etnográficos preveem procedimentos abertos referentes à pesquisa, à interação com os contextos investigados e à inspiração em diferentes áreas de conhecimento para produzir suas análises. Esse cruzamento metodológico permite focar um único evento - o processo de adoção da inovação em ensino e aprendizagem -, compilando uma descrição detalhada da dimensão individual de um profissional docente que compartilha a cultura de uma Instituição de Ensino Superior-IES, e a dimensão institucional na qual está inserido. O contexto pessoal, social e histórico, relatado a partir dos participantes que compartilham daquela cultura, fornece um quadro geral de como funciona aquele sistema numa perspectiva longitudinal. $O$ artigo focaliza uma alternativa de coleta de dados em substituição à aplicação de entrevistas, preservando-se a identidade dos sujeitos de pesquisa, e evitando-se exposição presencial ao pesquisador ou constrangimento ao posicionarem sua opinião frente a pares e gestores. Trata-se da seleção de relatos autoetnográficos que evocam episódios etnográficos dos sujeitos participantes, numa coconstrução de um período de vinte anos na IES.
\end{abstract}

Palavras-chave: Pesquisa Autoetnográfica; Procedimentos Etnográficos; Análise do Discurso; Inovação; Ensino e Aprendizagem.

\section{CHALLENGES AND POSSIBILITIES OF AUTOETNOGRAPHIC RESEARCH}

\begin{abstract}
This paper describes a qualitative research methodology with an interpretive framework based on social constructivism, in which the researcher seeks understanding of the world in which they live and work and develop subjective meanings of their experiences. In this context, we brought together procedures from autoethnography and ethnography, as well as techniques from discourse analysis, based on the idea that, in order to yield analyses, ethnographic studies require open procedures toward research, interactions with the investigated contexts, and inspiration drawn from different knowledge areas. This methodological breadth allowed us to focus on a single event-the process of adopting innovation in teaching and learning-compiling a detailed description of the individual dimension of a faculty member who shares the culture of a $\mathrm{HEI}$, and the institutional dimension in which the member is located. The personal, social, and historical contexts, recounted by the research subjects who shared in that culture, provide a general overview of how that HEl's institutional system works from a longitudinal perspective. The article focuses on an alternative data collection to replace the application of interviews, preserving the identity of the research subjects, and avoiding face-to-face exposure to the researcher or embarrassment when positioning their opinion before peers and managers. It deals with the selection of autoetnographic narratives that evoke ethnographic episodes of the participating subjects, in a co-construction of a period of twenty years in the $\mathrm{HEI}$.
\end{abstract}

Keywords: Autoethnographic Research; Ethnographic Procedures; Discourse Analysis; Innovation; Teaching and Learning. 


\section{INTRODUÇÃO}

A narrativa autoetnográfica ainda é raramente empregada em pesquisas em educação no Brasil. A falta de familiaridade dos avaliadores com tal forma de representação e a utilização do próprio pesquisador como fonte de dados são alguns dos motivos. Também a narrativa autoetnográfica evocativa ou emocional, proposta e divulgada inicialmente, na literatura, pode ter como resultado impedir ou ao menos dificultar outras maneiras de se conduzir pesquisas autoetnográficas (Anderson, 2006). Em vista disso, diversos desafios se impõem aos procedimentos desse tipo de pesquisa qualitativa.

Neste artigo, o desafio se apresenta quando da submissão do projeto de pesquisa ${ }^{1}$ ao Comitê de Ética em Pesquisa, este não autorizou as entrevistas presenciais para a coleta de dados etnográficos dos sujeitos de pesquisa, alegando que os sujeitos poderiam se sentir constrangidos ao posicionarem sua opinião frente a pares e gestores, num provável encontro em grupo, visto que o pesquisador atuava como professor na mesma instituição de ensino onde a pesquisa seria realizada.

Nesse contexto, este artigo visa descrever os procedimentos da coleta de dados por meio da seleção de relatos autoetnográficos que evocam episódios etnográficos dos sujeitos participantes, numa coconstrução de um período de vinte anos na Instituição de Ensino Superior - IES.

\section{ASPECTOS TEÓRICOS E CARACTERÍSTICAS DOS PROCEDIMENTOS AUTOETNOGRÁFICOS E ETNOGRÁFICOS ADOTADOS PARA A PESQUISA QUALITATIVA}

A autoetnografia é um método de pesquisa que se caracteriza por usar a experiência pessoal do pesquisador para descrever crenças, práticas e experiências culturais; valorizar os relacionamentos do pesquisador com os outros; usar a autorreflexão profunda e cuidadosa, denominada reflexividade, para nomear e questionar as intersecções entre o eu e a sociedade, o particular e o geral, o pessoal e o político; relatar o processo de descoberta do que fazer, de como viver e do significado das lutas das pessoas; equilibrar rigor, emoção e criatividade intelectuais e metodológicos em estilo literário (Adams, Jones, \& Ellis, 2015).

\footnotetext{
1 Este artigo é parte da tese intitulada "O percurso de adoção da inovação em ensino e aprendizagem por professores da educação superior a partir de currículos por competências", defendida em fevereiro de 2020 no Programa de Pós-Graduação em Educação da Pontifícia Universidade Católica do Paraná
} 
Portanto, os procedimentos de autoetnografia requerem reconhecer que "somos parte daquilo que estudamos" e "mais honestos enquanto pesquisadores, quando reconhecemos que nossas vidas pessoais e emoções estão entrelaçadas de inúmeras formas a quem, o que e como estudamos" (Adams et al., 2015, p. 15).

A reflexão, na autoetnografia, contextualiza a voz do indivíduo e do grupo na experiência vivida; dessa forma, a reflexão pessoal não se torna uma verdade única, mas a reflexão sobre os discursos pessoais analisados como grupo. O problema construído gera questões sobre a interpretação de como os outros irão analisar o próprio pesquisador, já que o pesquisador toma parte em duas configurações: a de observador e a de observado (por ele mesmo).

Atualmente, os textos etnográficos começam a refletir como "o eu e o campo se tornam um" (Adams et al., 2015, p. 10), ou seja, como auto e etnografia se mesclam. Os registros são "papéis que documentam e legitimam a experiência etnográfica e, ao mesmo tempo, as ambiguidades da relação mantida ao longo da pesquisa de campo". Eles contém marcas que necessitam ser interpretadas. Estas permitem ao pesquisador reconhecer "temporalidades múltiplas inscritas em eventos e estruturas sociais transformados em narrativas subsumidas à cronologia da história por meio de artifícios classificatórios" (Cunha, 2004, p. 304).

A etnografia deve "obter uma descrição densa, a mais completa possível sobre um grupo particular de pessoas e o significado das perspectivas imediatas que elas têm do que fazem" (Auroux, 1979, p. 11). E, como produto final de análise, obtém um retrato cultural envolvendo duas perspectivas: a dos participantes (emic) e a do pesquisador (etic); os termos emic e etic são abreviaturas de phonemic e phonetic. A abordagem emic focaliza a escuta atenta dos sujeitos, buscando compreender as categorias nativas dos significados. A abordagem etic significa o uso de categorias preestabelecidas para organizar e interpretar dados, no intuito de desenvolver uma interpretação do grupo a partir dos temas relacionados aos conceitos teóricos explorados numa pesquisa, e que neste caso, estão relacionados à inovação em ensino e aprendizagem a partir de currículos por competências. Tal interpretação é inferida a partir das palavras e ações dos grupos de pesquisados, considerando a tensão potencial entre o que fazem e o que deveriam fazer ou o que fazem e o que usam como artefatos (Creswell, 2014). A Figura 1 representa o cruzamento dos procedimentos mencionados. 


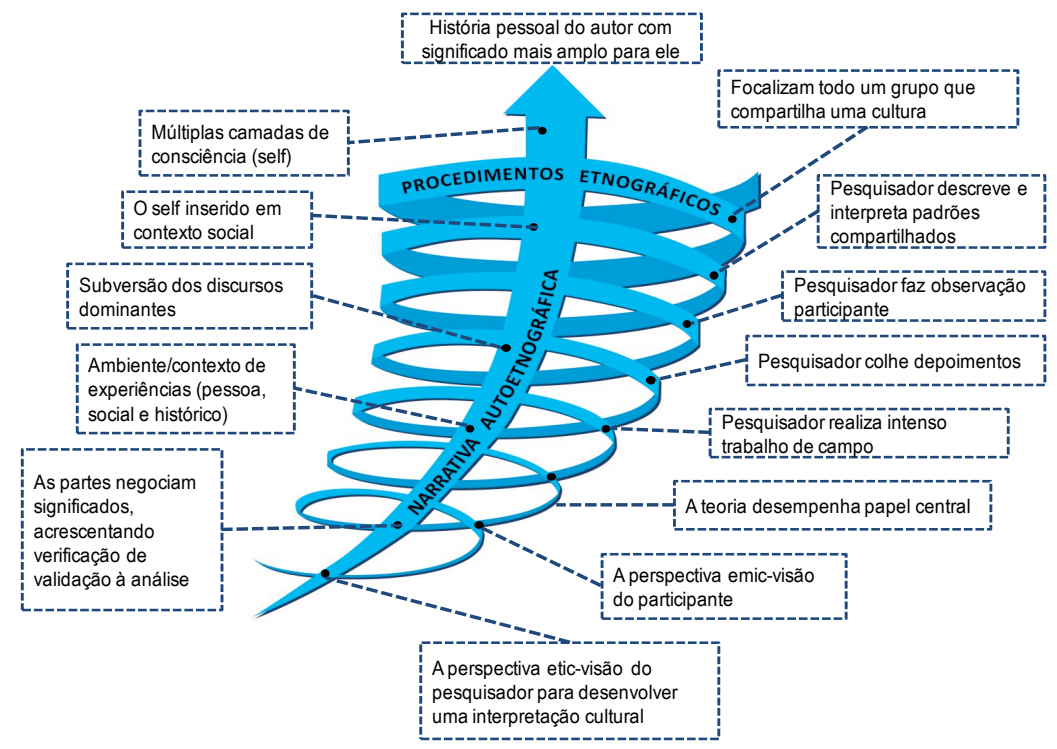

Figura 1. Características dos procedimentos etnográficos e autoetnográficos (Nicola, 2020).

\section{ENCAMINHAMENTO MEDODOLÓGICO DA PESQUISA AUTOETNOGRÁFICA}

Fez-se necessária a substituição da aplicação de entrevistas por coleta de episódios baseados em trechos da narrativa autoetnográfica. Tal decisão se justifica pela preservação da identidade dos sujeitos de pesquisa, evitando-se que sejam expostos presencialmente ao pesquisador ou que se sintam constrangidos ao posicionarem sua opinião frente a pares e gestores, num provável encontro em grupo, garantindo a ausência de conflito de interesses ou relações de poder entre os participantes e deles com o pesquisador.

O instrumento de pesquisa, elaborado a partir da narrativa autoetnográfica, estimula as lembranças do participante, provocando-o a não apenas fornecer respostas fechadas a partir de alternativas, mas também a relatar episódios que confirmam ou rejeitam o trecho narrativo autoetnográfico proposto na pesquisa; tais episódios são os chamados dados qualitativoetnográficos. Embora esse instrumento não permita uma abordagem mais aprofundada e completa como seria com a entrevista, representa uma estratégia de atenuação que contribui para a compreensão do contexto cultural e do módus operandi docente e institucional em torno do processo de adoção da inovação no ensino e aprendizagem a partir de currículos por competência na IES, foco da pesquisa. 


\subsection{Produção e Validação Interna da Coleta Autoetnográfica}

Toma-se a narrativa autoetnográfica da pesquisadora e docente da IES, como um instrumento de coleta de dados que evoca eventos relacionados a processos formativos e experiências pessoais, relacionais e emotivas sobre o processo de adoção da inovação em ensino e aprendizagem por professores de uma IES privada brasileira a partir de currículos por competências. Embora a memória seja falível, sendo impossível lembrar de todos os eventos e narrá-los numa linguagem que represente exatamente como esses eventos foram vividos e sentidos, é preciso reconhecer a importância da memória enquanto dado de pesquisa (Santos, 2017).

A narrativa relata fatos e situações sociais em seus ambientes naturais (no caso, a IES), assumindo explicitamente o uso da pessoalidade em busca da interpretação de fenômenos segundo a perspectiva docente, visto que se trata não apenas de um observador, mas de um participante ativo. Para tanto, alguns artefatos culturais presentes na rotina do docente são utilizados, tais como agendas pessoais, o currículo Lattes e os diferentes modelos de planos de ensino propostos pela IES no período de 2001 a 2017. Também são empregadas as notas de campo escritas no período de abril de 2016 a dezembro de 2017, quando a pesquisadora atuou como membro do setor de formação continuada da IES. Considerando a importância de proteção à privacidade e segurança dos sujeitos da pesquisa, fez-se necessário alterar características de identificação das pessoas mencionadas na narrativa que contém 18 páginas e está estruturada conforme a Tabela 1.

Tabela 1. Estrutura da narrativa (Nicola, 2020).

\begin{tabular}{llc}
\hline Períodos & Subtítulos & Páginas \\
\hline- A vivência do narrado é verdadeira $_{2001}$ & $\begin{array}{l}\text { Quando um encontro vale por uma formação continuada... } \\
\text { Um Programa de Aprendizagem à altura das expectativas... }\end{array}$ & 2 \\
\hline $2001-2011$ & Lembranças da formação institucional & 1 \\
\hline $2012-2014$ & A formação para a inovação numa estrutura mais integrada & 2 e $1 / 2$ \\
\hline & $\begin{array}{l}\text { Um programa de formação institucional: da inovação no ensino para o ensino } \\
\text { inovador }\end{array}$ & 2 e $1 / 2$ \\
& $\begin{array}{l}\text { O aconselhamento pedagógico na escrita das competências } \\
\text { O aconselhamento pedagógico no desdobramento dos elementos de } \\
\text { competência }\end{array}$ & 1 \\
& $\begin{array}{l}\text { Preparação do currículo para a elaboração dos resultados de aprendizagem: } \\
\text { uma possibilidade }\end{array}$ & 2 \\
& $\begin{array}{l}\text { O aconselhamento pedagógico para a criação da Matriz de resultados de } \\
\text { aprendizagem } \\
\text { O aconselhamento pedagógico para a criação de resultados de aprendizagem } \\
\text { Indicadores de desempenho: criação de docentes apoiados pelos NDE }\end{array}$ & 1 e $1 / 2$ \\
& & 2 \\
\hline
\end{tabular}


A tabela 1 revela não haver igual proporção de extensão na narrativa para os períodos, visto que o período de 2001 a 2011 corresponde a 16,6\% da extensão total, enquanto os outros $83,4 \%$ se referem ao período de 2012 a 2017.

Isso porque são relatados somente episódios marcantes para a pesquisadora no sentido de inovação no ensino e aprendizagem a partir de currículos por competências.

Dessa forma, faz-se uma retrospectiva de como se organizava o trabalho docente, como ocorreu o ingresso da autora na IES, quais desafios se impuseram em sua trajetória para se inserir na cultura universitária e como as experiências de se sentir desafiada a adotar mudanças curriculares por competências foram vividas por ela. Sua experiência vivida é elaborada analiticamente (Santos, 2017), como pesquisadora, registrando informações sobre a gestão das relações, da inovação e da busca por qualidade no cotidiano de trabalho da IES, em cada período.

Assim, no caso desta narrativa autoetnográfica, a distância temporal registra a diferença entre o estatuto que se tinha quando a experiência foi vivida (a condição de docente recémcontratada buscando adaptar-se) e o que se passou a ter quando o registro sobre tal experiência foi produzido (a condição de doutoranda em busca de evidências empíricas que sustentem um argumento analítico.

Para validar essa narrativa autoetnográfica, fez-se uma análise do documento com uso do software ATLAS.ti 8.0 a partir das categorias teóricas expostas na Tabela 2.

Tabela 2. Categorias teóricas da pesquisa (Nicola, 2020).

\begin{tabular}{|c|c|c|c|}
\hline NIVEL INSTITUCIONAL & & NÍVEL INDIVIDUAL & \\
\hline $\begin{array}{l}\text { ASPECTOS } \\
\text { GERENCIAIS (AG) }\end{array}$ & $\begin{array}{l}\text { DECISÕES } \\
\text { INSTITUCIONAIS } \\
\text { PEDAGÓGICAS (DIP) }\end{array}$ & $\begin{array}{l}\text { ASPECTOS DE ENSINO } \\
\text { E APRENDIZAGEM } \\
\text { (AEA) }\end{array}$ & $\begin{array}{l}\text { ASPECTOS RELACIONAIS } \\
\text { (AR) }\end{array}$ \\
\hline $\begin{array}{l}\text { AG-Formação } \\
\text { continuada dos } \\
\text { professores e gestores } \\
\text { como projeto } \\
\text { institucional } \\
\text { AG-Processos reflexivos } \\
\text { de autoria sobre seus } \\
\text { devires profissionais e } \\
\text { pessoais em educação } \\
\text { superior } \\
\text { AG- Espaço acadêmico } \\
\text { Processo de } \\
\text { transformação e } \\
\text { renovação do espaço } \\
\text { acadêmico } \\
\text { AG- Investimento na } \\
\text { pessoa e no saber da } \\
\text { experiência }\end{array}$ & $\begin{array}{l}\text { DIP-Caráter da } \\
\text { competência } \\
\text { Caráter polissêmico, } \\
\text { amorfo e plástico da } \\
\text { competência } \\
\text { DIP-CC-Uso em } \\
\text { variados sentidos } \\
\text { DIP-CC- } \\
\text { Recontextualização de } \\
\text { discursos } \\
\text { DIP-CC-Hibridização de } \\
\text { discursos }\end{array}$ & $\begin{array}{l}\text { AEA-Critérios de } \\
\text { experiências inovadoras } \\
\text { em educação } \\
\text { AEA-CEI-Rupturas com } \\
\text { modelo tradicional de } \\
\text { ensinar e aprender } \\
\text { positivista; } \\
\text { AEA-CEI-Gestão } \\
\text { participativa de sujeitos } \\
\text { protagonistas da } \\
\text { experiência, desde a } \\
\text { concepção até a análise } \\
\text { de resultados; } \\
\text { AEA-CEI-Reconfiguração } \\
\text { de saberes } \\
\text { AEA-CEI-Reorganização } \\
\text { da relação teoria e prática, }\end{array}$ & $\begin{array}{l}\text { AR-Abordagem de construção } \\
\text { curricular coletiva } \\
\text { AR-ACC-Cultura de gestão } \\
\text { curricular colegiada tradicional } \\
\text { AR-ACC-Cultura de } \\
\text { participação coletiva curricular } \\
\text { inovadora } \\
\text { AR-ACC-Ações colegiadas } \\
\text { permanentes de formação } \\
\text { AR-ACC-Análise coletiva do } \\
\text { currículo e da prática docente } \\
\text { AR-ACC-Planejamento } \\
\text { coletivo } \\
\text { AR-ACC-Formação de times } \\
\text { de professores (team } \\
\text { teaching) organizados na } \\
\text { mesma e/ou entre diferentes } \\
\text { áreas do saber }\end{array}$ \\
\hline
\end{tabular}




\begin{tabular}{|c|c|c|c|}
\hline $\begin{array}{l}\text { Desenvolvimento } \\
\text { pessoal, argumentando } \\
\text { a relevância de se } \\
\text { investir na pessoa e de } \\
\text { se considerar o saber da } \\
\text { experiência. }\end{array}$ & & $\begin{array}{l}\text { rompendo com teoria deve } \\
\text { preceder a prática; } \\
\text { AEA-CEI-Perspectiva } \\
\text { orgânica do processo de } \\
\text { concepção, } \\
\text { desenvolvimento e } \\
\text { avaliação da experiência } \\
\text { desenvolvida } \\
\text { AEA-CEI-Mediação entre } \\
\text { subjetividade e } \\
\text { conhecimento dos sujeitos } \\
\text { AEA-CEI-Protagonismo } \\
\text { dos estudantes como } \\
\text { sujeitos da prática } \\
\text { pedagógica e de suas } \\
\text { aprendizagens }\end{array}$ & $\begin{array}{l}\text { AR-ACC-Integração curricular } \\
\text { por meio da relação teoria- } \\
\text { prática } \\
\text { AR-ACC-Cultura do currículo } \\
\text { dinâmico } \\
\text { AR-ACC-Gerenciamento } \\
\text { democrático e longitudinal } \\
\text { (decisões consensuais) } \\
\text { AR-ACC-Compartilhamento } \\
\text { de responsabilidades sobre o } \\
\text { currículo } \\
\text { AR-ACC-Autorregulação } \\
\text { significativa e sistêmica } \\
\text { AR-Flexibilidade } \\
\text { AR-Interdisciplinaridade } \\
\text { AR-Contextualização }\end{array}$ \\
\hline $\begin{array}{l}\text { AG-Teoria da inovação } \\
\text { disruptiva } \\
\text { AG- Inovações } \\
\text { sustentadoras } \\
\text { AG-Retroação entre } \\
\text { inovação sustentada e } \\
\text { disruptiva }\end{array}$ & $\begin{array}{l}\text { DIP-Competência como } \\
\text { agir integrado de } \\
\text { saberes } \\
\text { DIP-Adoção } \\
\text { institucional do enfoque } \\
\text { conceitual de } \\
\text { competência } \\
\text { DIP-Escolha consciente } \\
\text { consensual docente } \\
\end{array}$ & $\begin{array}{l}\text { AEA-AF- Avaliação } \\
\text { formativa (AF) sustentada }\end{array}$ & $\begin{array}{l}\text { AR-FCL-Forte coordenação e } \\
\text { liderança inspiradora para } \\
\text { coesão das equipes de } \\
\text { professores } \\
\text { AR-FCL-Capacidade de } \\
\text { influência sobre o sistema } \\
\text { organizacional } \\
\text { AR-FCL-Interpenetração } \\
\text { consistente de valores }\end{array}$ \\
\hline $\begin{array}{l}\text { AG- Perspectiva } \\
\text { interacionista de modelo } \\
\text { de decisão } \\
\text { Teoria institucional }\end{array}$ & $\begin{array}{l}\text { DIP-MTC-Matrizes } \\
\text { teórico-conceituais na } \\
\text { organização curricular } \\
\text { por competências } \\
\text { (Deluiz, 1993; Tobón, } \\
\text { 2005) }\end{array}$ & em motivação & $\begin{array}{l}\text { AR-VMC-Validação da matriz } \\
\text { curricular por competências } \\
\text { durante e após sua } \\
\text { construção }\end{array}$ \\
\hline
\end{tabular}

Realizou-se análise análise temática (Bardin, 2002), que consiste na seleção de unidades de sentido da narrativa autoetnográfica relacionadas com as categorias teóricas desta pesquisa, as quais geraram um livro de códigos no ATLAS.ti.

Foram encontradas todas as categorias teóricas referentes ao nível institucional, tanto em relação a aspectos gerenciais como quanto a decisões institucionais pedagógicas; considerase esse resultado coerente e, de certa forma previsível, visto que o fio condutor da narrativa é a adoção da inovação a partir de currículos numa abordagem por competências. Também o nível individual quanto aos aspectos relacionais contemplou todas as categorias teóricas na narrativa, o que também se revela coerente, pois esses aspectos representam desdobramentos da abordagem de construção curricular coletiva e da validação da matriz curricular por competências.

\subsection{Produção e Validação da Coleta Etnográfica}

O instrumento de coleta de dados etnográficos foi organizado com duas partes: uma de abertura e outra contendo os trechos de relatos selecionados da narrativa autoetnográfica, 
orientada pelo referencial teórico da . Na primeira parte, a abertura visa esboçar o perfil dos sujeitos respondentes, por meio de alternativas que descrevem as prováveis atribuições que eles exercem ou já exerceram na IES em questão, buscando situá-los nos grupos 1 a 9 , conforme suas funções na IES, porém todos com o mesmo tempo de vínculo que a pesquisadora (vinte anos ou mais), conforme se apresenta na Tabela 4.

Na segunda parte, a estrutura das questões permite respostas quantitativas e qualitativas, a partir do seguinte comando padrão proposto após cada trecho relatado: "A relação entre esse relato e a minha experiência nesta IES é". São questões escalonadas, ou seja, as alternativas estão organizadas em escala, de maneira que o respondente indique o seu posicionamento diante de cada trecho de relato autoetnográfico, a saber: 0 (nenhuma), 1 (muito pouca), 2 (pouca), 3 (média), 4 (grande) e 5 (muito grande). Além disso, inserirem-se, entre parênteses, em cada alternativa, uma afirmação que estabelece contexto específico com o relato. Também em cada questão, após as alternativas, apresenta-se a possibilidade de resposta aberta, que permite explorar com profundidade o tema da adoção da inovação de ensino e aprendizagem a partir de currículos por competência: "Se você respondeu qualquer alternativa entre 1 e 5 , relate um episódio por você na IES, buscando comprovar ou negar o relato lido anteriormente. " Assim, ao assinalar seu posicionamento, o respondente aciona a memória em busca de fatos que vivenciou e decide escrever ou não um episódio. Exclusivamente, para orientar o respondente é que foi criada a parte de respostas quantitativas neste instrumento de pesquisa, pois somente os episódios etnográficos foram considerados para análise.

Faz-se necessário validar os seguintes aspectos do instrumento de coleta de dados: a clareza das instruções para que o participante responda de forma autônoma; a aplicação em ambiente semelhante ao utilizado durante a pesquisa; avaliação do tempo médio dispendido para responder à pesquisa; e adequação de termos institucionais (órgãos, departamentos e eventos) presentes nos trechos relatados, conforme o período histórico da IES. Para tornar perceptíveis essas e outras dificuldades particulares, é essencial o contato com respondentes que possuam características semelhantes às da população alvo. Por essa razão, dois docentes fizeram o teste-piloto no Qualtrics ${ }^{2} \AA$, enviando por email suas observações sobre o instrumento de pesquisa, antes de serem feitos os convites aos demais participantes. A

\footnotetext{
${ }^{2}$ A escolha do Qualtrics se justifica por ser uma ferramenta online que possibilita criar, distribuir, controlar as respostas recebidas e tratar os dados, disponibilizando, em sua versão gratuita, uma variedade de funções.
} 
Tabela 3 apresenta as questões nas quais foram propostas alterações e também as modificações realizadas.

Tabela 3. Aspectos que sofreram alterações na validação (Nicola, 2020).

Sugestões de alterações

Quando da apresentação da primeira pergunta baseada em seu relato (R2), você coloca, antes das alternativas, a frase "A relação entre esse relato e a minha experiência nesta IES é:". Esta frase é somente colocada naquela pergunta. Acho que ajudaria se ela aparecesse em todas as perguntas, antes das alternativas, pois, às vezes, fica estranha a passagem direta do relato para as alternativas.

Após cada seção de alternativas, há a frase "Se você respondeu qualquer alternativa entre 1 e 5 , relate um fato vivenciado por você na IES, buscando comprovar ou negar o relato lido anteriormente." O entendimento do que se trataria o "fato vivenciado" para mim não foi claro. Se interpretado como "episódio", me obrigaria a relatar uma história factual, como uma reunião específica, um documento escrito, etc. onde vivenciei aquilo.

Na questão R9 fala-se em "departamento". A IES, no período em que trabalhei nela (desde 1999), jamais foi dividida em departamentos, mas em "Centros" e seus respectivos cursos.

Há uma questão na qual se refere ao "Comitê de Inovação Acadêmica". Acredito que esteja se referindo ao CIG Comitê de Inovação na Graduação.
Alterações realizadas

"A relação entre esse relato e a minha experiência nesta IES é:" foi inserida nas 25 questões.

A frase foi alterada para "Se você respondeu qualquer alternativa entre 1 e 5, relate um episódio vivenciado por você na IES, buscando comprovar ou negar o relato lido anteriormente."

A primeira frase do $\mathrm{R} 9$ foi alterada para:

"Decididamente, a mudança da estrutura organizacional da IES passando de centros para escolas fez diferença! "E mais adiante: Antes, meu horizonte era o meu curso e o meu Centro.

A primeira frase do R14 foi alterada para: "A segunda iniciativa demandada pela Pró-Reitoria de Graduação foi organizar oficinas de formação sobre os cinco capítulos do livro de Scallon para o CIG - Comitê de Inovação na Graduação."

O teste piloto mostrou que o instrumento de pesquisa, apesar de validado internamente quanto às categorias teóricas, conforme relatado, ainda necessitava de alterações estruturais, levando por consequência, a um refinamento de sua adequação.

\subsection{Aplicação do Instrumento de Coleta de Dados}

O recrutamento e a seleção da amostra foram realizados por email, sendo que os interessados em participar da pesquisa, fizeram isso de forma anônima.

Foram enviados 120 emails, sendo que 75 responderam a todas as questões, conforme perfis indicados na Tabela 4. 
Tabela 4. Perfis dos respondentes da pesquisa (Nicola, 2020).

\begin{tabular}{clr}
\hline Grupos & Perfis dos profissionais & Total \\
\hline 1 & Atuais coordenadores de curso superior e de outros programas & 12 \\
2 & Atuais decanos & 2 \\
3 & Atuais membros do NEP & 5 \\
4 & Ex-coordenadores de curso professores integrantes do quadro docente. & 12 \\
5 & Ex-decanos professores integrantes do quadro docente. & 8 \\
& $\begin{array}{l}\text { Ex-diretores de centros, atualmente, ex-integrantes do quadro docente da IES que } \\
\text { atuaram em formação de professores, elaboração de documentos e decisões }\end{array}$ & 8 \\
& $\begin{array}{l}\text { pedagógicas. } \\
7\end{array}$ & $\begin{array}{l}\text { Membros e ex-membros tanto de NDE como de NEP, todos professores integrantes do } \\
\text { Professores integrantes do quadro docente com 20 anos ou mais de vínculo na IES e }\end{array}$ \\
8 & $\begin{array}{l}\text { participantes de formações continuadas, elaboração de documentos e decisões } \\
\text { pedagógicas. }\end{array}$ & 11 \\
9 & $\begin{array}{l}\text { Membros e ex-membros de NDE de cursos de graduação, responsáveis pela } \\
\text { reformulação dos currículos por competências no periodo de 2011 a 2017, todos } \\
\text { professores integrantes do quadro docente. }\end{array}$ & 14 \\
\end{tabular}

\subsection{Relato da Análise dos Dados Etnográficos}

Geraram-se automaticamente 67 códigos, sendo: 42 categorias teóricas, organizadas em 4 grupos, conforme a e 25 questões referentes a 789 episódios coletados, distribuídos nos 3 períodos de reformulação curricular da IES, a saber: 2000-2005 (247 episódios), 2006-2011 (71) e 2012-2017 (471 episódios).

Esse processo de codificação é importante para a técnica de Análise do Discurso empregada, pois permite identificar aspectos relevantes, mas que nem sempre serão utilizados. Na etapa seguinte, foi realizada a criação das unidades de registro a partir de da seleção de trechos marcados em cada episódio, permitindo sua localização posterior. De acordo com Bardin (2002), para que uma unidade de registro faça sentido, é preciso explicitar seu contexto; assim, a seleção de um trecho imediatamente anterior e/ou posterior é chamada de unidade de contexto.

Em seguida, por meio do gerenciador de códigos do ATLAS.ti, formaram-se os grupos de perfis de respondentes (). Posteriormente, criaram-se, por meio do gerenciador de redes do ATLAS.ti, os grupos de redes, relacionando os relatos desses grupos aos códigos das categorias teóricas correspondentes. $\mathrm{E}$, finalmente, formaram-se as redes de episódios em torno de uma ou mais categorias teóricas, sempre indicando os períodos de reformulação curricular em que se situam os episódios

Essas redes foram construídas a partir de duas categorias empíricas, ou seja, que emergem dos dados: as reações explícitas e implícitas dos docentes integrantes e ex-integrantes da IES e as reações organizacionais frente à inovação em ensino e aprendizagem a partir de currículos por competências.

A partir desse relato de tratamento de dados com uso do software ATLAS.ti, todas as correlações e análises são conduzidas a partir do referencial teórico desta pesquisa e da interpretação dos dados 
com base em elementos de análise do discurso. Entende-se não haver um sentido único do enunciado nem que ele está fixado na palavra; o sentido é um elemento simbólico, sempre incompleto, porque não é fechado nem exato.

Nessa perspectiva de que o enunciado não diz tudo, esta pesquisa busca identificar os efeitos de sentido e, para isso, necessita sair do enunciado e chegar ao enunciável por meio da interpretação. Assim, à medida que se fazem as leituras detalhadas para a análise horizontal dos episódios, faz-se também a seleção das marcas linguísticas ou marcas do discurso, para analisá-las, relacionando-as ao contexto sócio-histórico.

Assim, dos 75 respondentes do instrumento de pesquisa, 52 relataram episódios, sendo que cada relato autoetnográfico recebeu em média 26 , possibilitando variedade de informações e perspectivas em cada questão do instrumento de pesquisa.

Finalmente, sobre os perfis dos respondentes (Tabela 4), após a coleta e organização dos episódios, foi possível reordená-los em 6 grupos: atuais coordenadores; ex-coordenadores; atuais e ex-decanos; membros e ex-membros de NEP e NDE; docentes da IES; e ex-integrantes da IES. Assim, entendese que, mesmo que na época dos fatos relatados não estivessem exercendo esses cargos, o fato de hoje estarem na condição de um desses grupos os faz avaliar o passado a partir de suas visões de mundo vinculadas às suas atribuições na IES, sendo preciso analisá-las conforme o contexto históricosocial e as condições de produção de cada perfil.

\section{CONSIDERAÇÕES FINAIS}

A coleta de episódios etnográficos baseados em trechos da narrativa autoetnográfica, como alternativa de substituição de entrevistas revelou-se eficiente, visto que não só permitiu preservar a identidade dos sujeitos de pesquisa, mas também favoreceu que os participantes relatassem o vivido, avaliando-o a partir de seus momentos recentes, influenciados pelo conhecimento e pelo contexto atual. Para tanto, como ficou evidenciado, faz-se necessário rigor metodológico na seleção dos trechos da narrativa autoetnográfica, pois necessitam estar articulados com o referencial teórico da pesquisa. Considera-se que toda narrativa autoetnográfica reflete um movimento ora ordenado ora sobreposto de atos, emoções e sensações que, ao ser fragmentada em trechos para que o instrumento de pesquisa possa ser aplicado, pode tornar os fatos estanques entre si. Por essa razão, cabe ordenar os trechos relatados numa ordem cronológica que favoreça as lembranças dos respondentes sobre os fatos relatados. Tratase de uma co-construção dos fatos sob a perspectiva das vozes do pesquisador e dos envolvidos, contribuindo para a compreensão de outros casos similares e para a ampliação das possibilidades de utilização da autoetnografia no campo da gestão da educação superior. 


\section{REFERÊNCIAS}

Adams, T. E., Jones, S. H., \& Ellis, C. (2015). Autoethnography: understanding qualitative research. New York: Oxford University Press, UK.

Anderson, L. (2006). Analytic autoethnography. Journal of Contemporary Ethnography, 35(4), 373-395. https://doi.org/10.1177/0891241605280449

Auroux, S. (1979). La sémiotique des encyclopedistes. Paris: Payot.

Bardin, L. (2002). Análise de conteúdo. Lisboa: Edições 70.

Creswell, J. W. (2014). Investigação qualitativa e projeto de pesquisa: escolhendo entre cinco abordagens ( $3^{\text {rd }}$ ed). Porto Alegre: Penso.

Cunha, O. M. G. (2004). Tempo imperfeito: uma etnografia do arquivo. Mana Online, 10(2), 287-322.

Deluiz, N. (1993). Formação profissional no Brasil: enfoques e perspectivas. Boletim Técnico Do Senac, 19(1).

Nicola, R. de M. S. (2020). O percurso de adoção da inovação em ensino e aprendizagem por professores da educação superior a partir de currículos por competências. (Tese Doutorado), Pontifícia Universidade Católica do Paraná, Curitiba.

Santos, S. M. A. (2017). O método da autoetnografia na pesquisa sociológica: perspectivas e desafios. PLURAL, Revista Do Programa de Pós-Graduação Em Sociologia Da USP, 24(1), 214-241.

Tobón, S. (2005). Formación basada en competencias: pensamiento complejo, diseño curricular y didactica. Bogotá: Ecoe Ediciones. 